\title{
ПАТОГЕНЕТИЧЕСКАЯ ТЕРАПИЯ ДИАРЕИ У ДЕТЕЙ В УСЛОВИЯ ПАНДЕМИИ COVID-19
}

Хавкина Д.А. ${ }^{1}$, Руженцова Т.А. ${ }^{1}$, Попова Р.В. ${ }^{1,2}$, Чухляев П.В. ${ }^{1}$, Гарбузов А.А. ${ }^{1}$, Мешкова Н.А. ${ }^{3}$

1 - ФБУН ЦНИИ Эпидемиологии Роспотребнадзора г. Москва,

2 - ГБУЗ МО ГБУЗ МО «МГКБ», г. Мытищи,

3 - ФГАОУ ВО Первый МГМУ имени И.М. Сеченова Минздрава России

(Сеченовский Университет)

Резюме

Цель исследования - изучить особенности нарушений функции желудочнокишечного тракта у детей, больных коронавирусной инфекцией, вызванной вирусом SARSCoV-2, и методы его коррекции с использованием желатина танната.

В статье представлен краткий обзор литературы по эффективности и безопасности применения желатина танната в комплексной терапии острых кишечных инфекций. Приведены данные собственных исследований по диагностике и лечению средне-тяжелой формы COVID-19 с развитием дисфункции ЖKT у детей в возрасте от 3 месяцев до 18 лет.

Материалы и методы

Проведен обзор литературных данных по эффективности и безопасности применения желатина танната в качестве патогенетической терапии при острых кишечных инфекциях у детей. Проанализированы данные историй болезней 36 детей, находившихся на лечении с диагнозом: внебольничная пневмония коронавирусной этиологии (вирус SARS-CoV-2 идентифицирован) в детском инфекционном отделении ГБУЗ МО «МГКБ» г. Мытищи. Возраст детей был от 8 месяцев до 17 лет. Пациенты получали терапию в условиях стационара в соответствии с действующими временными методическими рекомендациями по лечению COVID-19, утвержденными Минздравом РФ, по показаниям - другие лекарственные средства. Вирус SARS-CoV-2 был идентифицирован методом полимеразной цепной реакции (ПЦР). Представлен клинический пример эффективности желатина танната у пациента с коронавирусной инфекцией, вызванной SARS-CoV-2.

Результаты и обсуждение

Желудочно-кишечные нарушения проявлялись у пациентов на 4-5 день у 23х детей (64\%) и продолжалась от 3 до 5 дней. У большинства детей отмечали диарею (64\%) и боли в животе (57\%). Другие симптомы, свидетельствующие о дисфункции желудочно-кишечного тракта, были зарегистрированы у 67\% детей. Из представленного клинического примера следует, что желатина таннат у пациентов со средне-тяжелой формой COVID-19 с 
выраженной дисфункцией ЖКТ демонстрирует эффективность, что согласуется с данными литературы.

Выводы

Желудочно-кишечные нарушения имеются у большинства детей, госпитализированных с внебольничной пневмонией, вызванной вирусом SARS-CoV-2. Симптоматика купируется при проведении курса основной терапии, показанной для лечения COVID-19, и дополнительной, рекомендуемой при острых кишечных инфекциях.

Ключевые слова: абдоминальная боль, дети, диарея, коронавирус, пневмония, COVID-19, SARS-CoV-2, желатина таннат.

\section{PATHOGENETIC THERAPY IN CHILDREN IN THE CONTEXT OF THE COVID-19}

\section{PANDEMIC}

Ruzhentsova T.A., Khavkina D.A., Popova R.A., Chukhliaev P.V., Garbuzov A.A. Central research Institute of epidemiology, Federal Supervision Service for Consumer Rights Protection and People’s Welfare, RF, Moscow

Summary

The aim of the study was to study the features of gastrointestinal tract dysfunction in children with coronavirus infection caused by the SARS - CoV-2 virus and the effectiveness of tanatta gelatin in the treatment of acute intestinal infections, including those caused by the SARSCoV-2 virus.

The article presents a brief review of the literature on the effectiveness and safety of gelatin tannate in the complex therapy of acute intestinal infections. Data from our own research on the diagnosis and treatment of moderate form of CAVID-19 with the development of gastrointestinal dysfunction in children aged 3 months to 18 years are presented.

Materials and methods

A brief review of the literature on the effectiveness and safety of gelatin tannate as a pathogenetic therapy for acute intestinal infections in children was conducted. We analyzed data from the medical histories of 36 children who were treated with a diagnosis of community-acquired pneumonia of coronavirus etiology (SARS-CoV-2 virus identified). The children were aged from 8 months to 17 years. Patients were treated in a hospital setting in accordance with the current INTERIM guidelines for the treatment of COVID-19virus SARS-CoV-2 was identified by polymerase chain reaction (PCR). A clinical example of the effectiveness of gelatin tannate in a patient with a coronavirus infection caused by SARS-CoV-2 is presented.

Results and discussion 
Gastrointestinal disorders appeared in patients on day 4-5 in 23 children (64\%) and lasted from 3 to 5 days. Most children had diarrhea (64\%) and abdominal pain (57\%). Other symptoms indicating gastrointestinal dysfunction were reported in $67 \%$ of children. From the presented clinical example, it follows that gelatin tannat in patients with moderate-severe COVID-19 with severe gastrointestinal dysfunction demonstrates effectiveness, which is consistent with the literature data.

\section{Conclusions}

Gastrointestinal disorders are present in most children hospitalized with communityacquired pneumonia caused by the SARS-CoV-2 virus. Symptoms are relieved during the course of the main therapy indicated for the treatment of COVID-19, and additional, recommended for acute intestinal infections.

Keywords: abdominal pain, children, diarrhea, coronavirus, pneumonia, COVID-19, SARSCoV-2, gelatin tannate, acute intestinal infections.

\section{Введение}

Цель исследования - изучить особенности нарушений функции желудочнокишечного тракта у детей, больных коронавирусной инфекцией, вызванной вирусом SARS$\mathrm{CoV}-2$, и методы его коррекции с использованием желатина танната.

Нарушения функции желудочно-кишечного тракта (ЖКТ) часто сопровождают острые респираторные вирусные инфекции (ОРВИ). Чаще всего такое сочетание симптоматики встречается при ротавирусной инфекции, реже - при норавирусной, аденовирусной инфекции, бока- и метапневмовирусной инфекции, гриппе. Механизм вовлечения в инфекционно-воспалительный процесс может быть абсолютно различным[1-2]. Возможно, как непосредственное действие возбудителя на клетки ЖКТ с их поражением и последующим апоптозом, так и косвенное, посредством нарушений кровотока и нервной регуляции.

Действие вируса SARS-CoV-2 приходится преимущественно на рецепторы ангиотензин-превращающего фермента 2 типа (АПФ-2), которые присутствуют в разных тканях, на эндотелии кровеносных сосудов и в том числе на клетках эпителия ЖКТ, что может объяснить различие клинических проявлений. Почти с самого начала изучения новой коронавирусной инфекции стало понятно, что, наряду с симптомами поражения дыхательных путей и интоксикацией, у пациентов нередко отмечаются желудочнокишечные нарушения. В некоторых случаях бывает сложно определить, связаны ли клинические проявления с инфекционным агентом или же с проводимой терапией. Однако, вне зависимости от причины, обильная диарея и рвота могут привести к электролитному 
дисбалансу, метаболическим нарушениям и обезвоживанию с развитием гиповолемического шока [3]. Несмотря на практически отработанную схему лечения острых кишечных инфекций, их распространенность, последствия применения антибиотикотерапии требуют непосредственно патогенетической коррекции не только биоценоза, но и функционального, морфологического состояния ЖКТ. С этими задачами должны справляться сорбенты и смектиты, однако часто требуется более щадящий подход в виде смягчающего, цитомукопротективного действия на раздраженную слизистую ЖКТ. Препарат желатина танната обладает хорошей способностью механической защиты слизистой оболочки ЖКТ. Кроме того, многочисленные исследования показали, его способность восстанавливать баланс между секрецией и абсорбцией, предотвращая обезвоживание - главный риск осложнений ОКИ. В частности, С.В. Халиулина и соавт., которые исследовали 60 детей в возрасте от 3 месяцев до 14 лет с диагнозом ОКИ, применение Адиарина совместно с антибактериальной терапией, против стандартной схемы (антибиотикии совместно с сорбентами), установили, что продолжительность диарей в основной группе сократилась почти в 2 раза по сравнению с контрольной группой $(p=0,006)[1]$. В исследовании М.К. Бехтеровой и соавт., Адиарин существенно сокращал длительность диарейного синдрома $(3,6 / 4,7)$, лихорадки $(1,9 / 2,45)$, синдром абдоминальных болей $(1,5 / 2,76)(p=0,05 ;$ показатели в сутках)[3-5].

\section{Клинический пример 1}

Девочка К., возраст 6 лет, при осмотре, со слов мамы, жалуется на жидкий водянистый стул до 8 раз за сутки, тошноту, рвоту пищей до 5 раз в сутки, отсутствие аппетита, общую слабостьт, головную боль, повышение температуры тела до $38,2^{\circ} \mathrm{C}$. Из анамнеза известно, что девочка заболела 2 дня назад, когда появились тошнота, рвота, затем появился жидкий стул, жалобы на слабость и повышение температуры тела. Объективно: Состояние ребенка средней тяжести. Кожа бледная, сухая. Губы сухие, язык обложен белым налётом. Температура тела $-37,9^{\circ} \mathrm{C}$. Вес - 21,2 кг. Частота дыхательных движений - 22 в минуту. Аускультативно в лёгких выслушивается пуэрильное дыхание, хрипов нет. Тоны сердца звучны, ритмичные, частота сердечных сокращений 108 ударов в минуту. Артериальное давление - 95/70 мм рт. ст. Живот мягкий, умеренно вздут, чувствительный при пальпации. Менингеальных и очаговых неврологических симптомов нет. Диагноз: острая кишечная инфекция, средне-тяжелая форма. Эксикоз 1 степени. Назначено лечение: адиарин регидрокомплекс, диоктаэдрический смектит 3 гр (1 пакетик) 3 раза в день, адиарин желатина таннат 0,25 (1 пакетик) 4 раза в день, пробиотический комплекс. Произведен расчёт жидкости: 50 мл х 21,2 = 1060 мл - за первые 6 часов, 80 мл х 21,2 = 1696 мл за 
следующие сутки. Учитывая преобладание водянистой диареи, адиарин регидрокомплекс должен составлять $1 \frac{2}{2}$ от рассчитанного объёма, или 530 мл за первые 6 часов лечения, затем - 848 мл за следующие сутки. Другая часть должна быть в виде питьевой воды либо некрепкого чая. После первых 6 часов на фоне терапии отмечается улучшение самочувствия ребёнка: температура тела $37,3^{\circ} \mathrm{C}$, губы влажные, рвоты нет, стул 2 раза - неоформленный. Спустя 30 часов отмечается нормализация температуры тела, стул в течение последних 24 часов - 3 раза.

Спустя 48 часов (конец 2-х суток терапии) отмечается устойчивая нормальная температура тела, отсутствие рвоты и диареи, улучшение аппетита, за предшествующие 24 часа стул 1 раз - полуоформленный. После купирование симптоматики регидратационная, цитомукопротективная и энтеросорбционная терапия завершена. Приём пробиотического комплекса продлен на 2 недели с целью восстановления возможных потерь микрофлоры.

\section{Клинический пример 2}

Мальчик Ж., 14 лет, при осмотре жалуется на слабость, плохое самочувствие, боли в животе, частый неоформленный стул, до 7 раз в сутки, тошноту, повышение температуры тела до $37,4^{\circ} \mathrm{C}$.

Из анамнеза известно, что мальчик болен 2-е сутки. Накануне появились боли в животе, неоформленный стул, несколько позднее повышение температуры тела. Проживает с отцом, у которого 7 дней назад была диагностирована коронавирусная инфекция (подтвержденная по результату ПЦР), двусторонняя интерстициальная пневмония, КТ-1. Объективно: Состояние удовлетворительное. Кожа бледная, сухая. Губы сухие, язык обложен белым налётом. Температура тела $-37,2^{\circ} \mathrm{C}$. Вес $-58,0$ кг. Сатурация кислорода 98\%.. Дыхание свободное, через нос. Зев - чистый, без особенностей. Частота дыхательных движений - 18 в минуту. Аускультативно в лёгких выслушивается везикулярное дыхание, хрипов нет. Тоны сердца звучны, ритмичны, частота сердечных сокращений 94 удара в минуту. Артериальное давление - 120/75 мм рт. ст. Живот мягкий, умеренно вздут, в проекции толстого кишечника умеренно болезненный при пальпации. Менингеальных и очаговых неврологических симптомов нет.

Диагноз: острая кишечная инфекция, средне-тяжелая форма. Коронавирусная инфекция, кишечная форма - ? Терапия: адиарин желатина таннат 0,5 (2 пакетика) 4 раза в день, адиарин регидрокомплекс 1450 мл в первые 6 часов, далее - по 2300 мл в сутки, адиарин пробио 6 капель в сутки. На фоне лечения в течение первых суток отмечается улучшение самочувствия. Однако, сохранилось повышение температуры тела до 37,5². 
Со 2-х суток появились чувство першения в горле, заложенность и выделения из носа, отмечает потерю обоняния. По результатам лабораторной диагностики в мазках на ПЦР из зева и носоглотки обнаружен вирус SARS-CoV-2. В схему лечения добавлены орошения носа и горла мирамистином 4 раза в сутки, умифеновир 0,2 - 4 раза в день. С 3-х суток наблюдается оформленный стул, 2 раза в сутки, боли в животе незначительные. С 4-х суток идет нормализация температура тела, стул оформленный 1 раз в сутки, болей в животе нет, чувства першения в горле не беспокоит.

Из клинических примеров мы можем наблюдать, что препарат Адиарин одинаково эффективен, как при острой кишечной инфекции, так и при кишечной форме COVID-19, которая нередко преобладает в детском возрасте.

Были проанализированы данные историй болезней 36 детей, находившихся на лечении с диагнозом: внебольничная пневмония коронавирусной этиологии (вирус SARSCoV-2 идентифицирован) в детском инфекционном отделении ГБУЗ МО «МГКБ» г. Мытищи с марта по июль 2020 года. Большинство пациентов имели средне-тяжелую форму заболевания (96\%), тяжелых форм не было. Возраст детей был от 8 месяцев до 17 лет. Большинство пациентов были в возрасте от 8 месяцев до 3 лет (36\%), 3 - 6 лет - 22\%, 6 - 10 лет - 14\%, 10 - 17 лет - 28\%. Длительность наблюдения на дому до момента госпитализации составляла от трех до восьми дней. Всем детям в 1-й день госпитализации были выполнены клинический осмотр, рентгенография или компьютерная томография (KT) легких, анализы крови клинический и биохимический, коагулограмма, общий анализ мочи, анализ мазка из зева и носа на вирус SARS-CoV-2 методом полимеразной цепной реакции (ПЦР). При наличии диареи проводили бактериологическое исследование кала для идентификации возбудителей кишечной группы (сальмонелл, шигелл, эшерихий, кампилобактера) и иммуноферментный анализ для исключения рота- или норавирусной инфекции. При выявлении каких-либо других возбудителей, помимо SARS-CoV-2, пациенты исключались из данного наблюдения.

В стационаре дети находились в течение 8 - 15 койко-дней до выздоровления или устойчивого улучшения с наличием не менее 2 отрицательных результатов анализа мазка из зева и носа на наличие вируса SARS-CoV-2. За этот период оценка клинического статуса проводилась не реже 1 раза в день, дополнительное обследование - не реже 1 раза в 7 дней, по показаниям - чаще.

Пациенты получали терапию в соответствии с временными методическими рекомендациями по ведению больных с COVD-19, при желудочно-кишечных нарушениях дополнительно, по показаниям, диета с исключением сырых фруктов и овощей, молочных 
продуктов и продуктов, стимулирующих газообразование, а также другие лекарственные средства. Всем детям была назначена антибактериальная терапия (цефалоспорины Цефтриаксон внутримышечно - в 98\%, макролиды - азитромицин перорально - в 2\%), пробиотики (Бифидумбактерин - в 89\%, Бак-сет - в 11\%,) и противовирусная терапия (Гриппферон назально - в 87\% или Кипферон - в 13\%). По диагнозу пневмония дети получали муколитики (в 97\%), антисептики (в 87\%), кортикостероиды (в 37\%), бронхолитики (в 64\%), антигистаминные препараты (в 25\% - 9 детей). При диарейном синдроме назначали стандартную оральную (50\%) или пероральную (15\%) регидратационную терапию, энтеросорбенты (диоктаэдрический смектит, Смекту или диоксид кремния коллоидный, Полисорб - 14\%). При гемоколите в схему лечения добавляли антигеморрагические средства (Викасол внутримышечно - в 13\%). При симптомах ферментативной недостаточности после купирования острой диареи назначали ферменты (Креон или Панкреатин - в 67\%). Парацетамол в качестве жаропонижающего средства дети получали при температуре более $38-39^{\circ} \mathrm{C}$, в соответствии с современными рекомендациями.

\section{Результаты и обсуждение}

Большая часть проведенных исследований подтверждает основные свойства препарата, такие как: сокращение длительности диарейного синдрома, более быстрое купирование симптомов общей интоксикации, в среднем, в 2 раза. Клинические примеры первого и второго пациента из собственной практики подтверждают данные литературы.

Несмотря на главный патологический процесс в виде вирусной пневмонии, COVID-19 у детей часто сопровождается нарушением функции ЖКТ. При анализе анамнеза и клинической картины в динамике было установлено, что диарея отмечалась с четвертыхпятых суток заболевания у 23 детей (64\%) и продолжалась от трех до пяти дней. Стул был жидким, слизистым, в единичных случаях (в 13\% от общего числа детей) с прожилками крови. Частота стула у большинства детей была до 5 раз в сутки, максимально - до 8 раз.

По данным литературных источников и собственных клинических примеров, Адиарин существенно сокращает длительность периода диареи, в среднем, за двое суток по сравнению со стандартной терапией ОКИ, в том числе с дисфункцией ЖKT на фоне COVID19 [6-8].

Купирование симптоматики на фоне продолжения противовирусной и антибактериальной терапии указывает на непосредственное участие коронавируса в патогенезе и может опровергать возможное влияние дисбиотических нарушений с активизацией роста условно-патогенной флоры, а также дисфункцию гепато-билиарной системы, что нельзя исключить при применении, в первую очередь, цефалоспоринов. 
Высокая частота регистрации желудочно-кишечных нарушений, у многих детей до начала терапии, подтверждает тропность нового коронавируса к ЖКТ. Большое число случаев дискомфорта в животе поле еды, тошноты, метеоризма, свидетельствует о, вероятно, развивающейся при коронавирусной ферментопатии и возможном вовлечении в инфекционно-воспалительный процесс поджелудочной железы и гепато-билиарной системы, что требует дальнейшего изучения[9,10].

\section{Выводы}

Желудочно-кишечные нарушения имеются у большинства детей, госпитализированных с внебольничной пневмонией, вызванной вирусом SARS-CoV-2. Диарея выявлена в 64\%, абдоминальный болевой синдром - у 57\%, другие симптомы, свидетельствующие о дисфункции желудочно-кишечного тракта, - в 67\%. Симптоматика купируется при проведении курса основной терапии, показанной для лечения COVID-19, и дополнительной, рекомендуемой при острых кишечных инфекциях.

В качестве эффективного и безопасного средства для коррекции дисфункции ЖКТ, в том числе на фоне COVID-19 можно рекомендовать в дополнение к базовой терапии препарат желатина танната (Адиарин).

\section{Сведения об авторах}

Попова Раиса Викторовна - лаборант - исследователь клинического отдела инфекционной патологии Федерального бюджетного учреждения науки «Центральный научно-исследовательский институт эпидемиологии» Федеральной службы по надзору в сфере защиты прав потребителей и благополучия человека; 111123, г. Москва, ул. Новогиреевская, д. ЗА; тел. +7-495-672-11-58; врач ГБУЗ МО ГБУЗ МО «МГКБ», г. Мытищи; e-mail: raiakotova@gmail.com ORCID: 0000-0003-3324-3554 .

Руженцова Татьяна Александровна - доктор медицинских наук, руководитель отдела клинических исследований, профессор образовательного центра Федерального бюджетного учреждения науки «Центральный научно-исследовательский институт эпидемиологии» Федеральной службы по надзору в сфере защиты прав потребителей и благополучия человека; 111123, г. Москва, ул. Новогиреевская, д. 3А; тел. +7-495-304-56-96; e-mail: ruzhencova@gmail.com; ORCID: 0000-0002-6945-2019.

Хавкина Дарья Александровна - статистик отдела клинических исследований Федерального бюджетного учреждения науки «Центральный научно-исследовательский институт эпидемиологии» Федеральной службы по надзору в сфере защиты прав 
потребителей и благополучия человека; 111123, г. Москва, ул. Новогиреевская, д. ЗА; тел. +7-495-304-56-96; e-mail: havkina@gmail.com; ORCID: 0000-0001-5919-9841.

Чухляев Павел Владимирович - методист отдела клинических исследований Федерального бюджетного учреждения науки «Центральный научно-исследовательский институт эпидемиологии» Федеральной службы по надзору в сфере защиты прав потребителей и благополучия человека; 111123, г. Москва, ул. Новогиреевская, д. ЗА; тел. +7-495-304-56-96; e-mail: pafachka@gmail.com, ORCID:0000-0003-1210-1215.

Гарбузов Александр Александрович - методист отдела клинических исследований Федерального бюджетного учреждения науки «Центральный научно-исследовательский институт эпидемиологии» Федеральной службы по надзору в сфере защиты прав потребителей и благополучия человека; 111123, г. Москва, ул. Новогиреевская, д. ЗА; тел. +7-495-304-56-96; e-mail: os.vertebra@mail.ru; ORCID: 0000-0002-3378-8418.

Мешкова Наталья Андреевна - студентка 3-го курса Клинического института детского здоровья им. Н.Ф. Филатова Федерального государственного автономного образовательного учреждения высшего образования «Первый Московский государственный медицинский университет имени И.М. Сеченова» Министерства здравоохранения Российской Федерации (Сеченовский университет); 119435, Москва, ул. Большая Пироговская, д. 2, стр. 4, тел. +7-903-520-07-46; e-mail: nataliaandreevnamesh@gmail.com; ORCID: 0000-0003-3904-7108.

\section{For correspondence}

Tatiana A. Ruzhentsova, Doctor of medical sciences, Head of clinical research Department, professor of Educational Center of Central Research Institute of Epidemiology, Russian Federal Supervision Service for Consumer Rights Protection and People's Welfare; Address: 3a, Novogireevskaya St., Moscow 111123, Russia; Telephone: +7-495-304-56-96; e-mail: ruzhencova@gmail.com; ORCID: 0000-0002-6945-2019.

Daria A. Khavkina, Statistic of clinical research Department of Central Research Institute of Epidemiology, Russian Federal Supervision Service for Consumer Rights Protection and People’s Welfare; Address: 3a, Novogireevskaya St., Moscow 111123, Russia; Telephone: +7-495304-56-96; e-mail: havkina@gmail.com; ORCID: 0000-0001-5919-9841.

Pavel V. Chukhliaev, Methodist of clinical research Department of Central Research Institute of Epidemiology, Russian Federal Supervision Service for Consumer Rights Protection and People’s Welfare; Address: 3a, Novogireevskaya St., Moscow 111123, Russia; Telephone: +7495-304-56-96; e-mail: pafachka@gmail.com, ORCID:0000-0003-1210-1215. 
Alexander A. Garbuzov, Methodist of clinical research Department of Central Research Institute of Epidemiology, Russian Federal Supervision Service for Consumer Rights Protection and People’s Welfare; Address: 3a, Novogireevskaya St., Moscow 111123, Russia; Telephone: +7495-304-56-96; e-mail: os.vertebra@mail.ru; ORCID: ORCID: 0000-0002-3378-8418.

Raisa V. Popova, Laboratory researcher, clinical Department of infectious pathology, Federal budget institution of science "Central research Institute of epidemiology" of Federal service for supervision of consumer rights protection and human well-being; 111123, Moscow, novogireevskaya str., d. 3A; tel: +7-495-672-11-58; doctor of GBUZ MO GBUZ MO "mgcb", Mytischi; e-mail: raiakotova@gmail.com ORCID: 0000-0003-3324-3554 .

Natalia A. Meshkova, Student of 3th course of Faculty "Institute of Children's Health", Federal State Autonomous Educational Institution of Higher Education First Moscow State Medical University named after I.M. Sechenov of the Ministry of Health of the Russian Federation (Sechenov University); 8, p. 2, Trubetskaya St., Moscow, 119991, Russia; e-mail: nataliaandreevnamesh@gmail.com

\section{Конфликт интересов}

Авторы заявляют об отсутствии конфликта интересов

\section{Conflict of interests}

The authors claim that there is no conflict of interest.

\section{Список литературы}

1. Tang $\mathrm{X}, \mathrm{Wu} \mathrm{C}$, Li $\mathrm{X}$, et al. On the origin and continuing evolution of SARS-CoV-2. National Science Review 2020.

2. World Health Organization. Director-General's remarks at the media briefing on 2019nCoV on 11 February 2020. https:/www.who.int/dg/speeches/detail/who-director-general-sremarks-at-the-media-briefing-on-2019-ncov-on-11-february-2020 (Accessed on February 12, 2020).

3. Хавкина Д.А., Руженцова Т.А., Чухляев П.В., Гарбузов А.А., Шушакова Е.К. Роль дезинтоксикационной и антиоксидантной терапии в лечении COVID-19: теория и практика. Эпидемиология и инфекционные болезни: актуальные вопросы. 2020: 62-69.

DOI: https://dx.doi.org/10.18565/epidem.2020.2.62-69.

4. Плоскирева А.А., Горелов А.В. Патогенетическая терапия острых кишечных инфекций у детей:комплексный подход // РМЖ. Медицинское обозрение. 2018. o 8(II). С. 79-82: 

infekciy u detey kompleksnyy podhod/.

5. Р. Г. Ловердо, Ю. В. Соловьев, К. Г. Штокалов, Н. Н. Сулима. Опыт применения и оценка эффективности желатина танната в лечении острых кишечных инфекций у детей. Детские инфекции. 2019; 18(1):38-41. https://doi.org/10.22627/2072-8107-2019-18-1-38-41.

6. Xiao F, Tang M, Zheng X, Liu Y, Li X, Shan H. Evidence for gastrointestinal infection of SARSCoV-2. Gastroenterology. 2020 DOI: 10.1053/j.gastro.2020.02.055.

7. Leung WK, To KF, Chan PK, et al. Enteric involvement of severe acute respiratory syndrome-associated coronavirus infection. Gastroenterology. 2003; 125: 1011-7. DOI: 10.1016/s0016-5085(03)01215-0.

8. Lu X, Zhang L, Du H, et al. SARS-CoV-2 Infection in Children. N Engl J Med. 2020. DOI: 10.1056/NEJMc2005073.

9. Zhang C, Shi L, Wang FS. Liver injury in COVID-19: management and challenges. Lancet Gastroenterol Hepatol. 2020. DOI: 10.1016/S2468-1253(20)30057-1.

10. $\mathrm{Xu} \mathrm{L,} \mathrm{Liu} \mathrm{J,} \mathrm{Lu} \mathrm{M,} \mathrm{Yang} \mathrm{D,} \mathrm{Zheng} \mathrm{X.} \mathrm{Liver} \mathrm{injury} \mathrm{during} \mathrm{highly} \mathrm{pathogenic} \mathrm{human}$ coronavirus infections. Liver Int. 2020. DOI: 10.1111/liv.14435.

\section{References}

1. Tang $\mathrm{X}, \mathrm{Wu} \mathrm{C}, \mathrm{Li} \mathrm{X}$, et al. On the origin and continuing evolution of SARS-CoV-2. National Science Review 2020.

2. World Health Organization. Director-General's remarks at the media briefing on 2019nCoV on 11 February 2020. https://www.who.int/dg/speeches/detail/who-director-general-sremarks-at-the-media-briefing-on-2019-ncov-on-11-february-2020 (Accessed on February 12, 2020).

3. Khavkina D.A.., Ruzhencova T.A., Chukhliaev P.V., Garbuzov A.A., Shushakova E.K. The role of detoxication and antioxidation therapy COVID-19: theory and practicea. Epidemiology and infection diseases: actual questions. 2020: 62-69. DOI: https://dx.doi.org/10.18565/epidem.2020.2.62-69.

4. Ploskireva A.A., Gorelov A.V. Pathogenetic therapy of acute intestinal infections in children: integrated approach // RMJ. Medical Review. 2018. No 8(II). P. 79-82: https://www.rmj.ru/articles/infektsionnye bolezni/Patogeneticheskaya terapiya ostryh kishechnyh infekciy u detey kompleksnyy podhod/.

5. R.G. Loverdo, Yu.V. Solovyev, K.G. Shtokalov, N.N. Sulima. Experience in the use and evaluation of the effectiveness of gelatine tannate in the treat-ment of acute intestinal infections in 
children. Detskie Infektsii=Children's Infections. 2019; 18(1):38-41 https://doi.org/10.22627/20728107-2019-18-1-38-41.

6. Xiao F, Tang M, Zheng X, Liu Y, Li X, Shan H. Evidence for gastrointestinal infection of SARSCoV-2. Gastroenterology. 2020 DOI: 10.1053/j.gastro.2020.02.055.

7. Leung WK, To KF, Chan PK, et al. Enteric involvement of severe acute respiratory syndrome-associated coronavirus infection. Gastroenterology. 2003; 125: 1011-7. DOI: 10.1016/s0016-5085(03)01215-0.

8. Lu X, Zhang L, Du H, et al. SARS-CoV-2 Infection in Children. N Engl J Med. 2020. DOI: 10.1056/NEJMc2005073.

9. Zhang C, Shi L, Wang FS. Liver injury in COVID-19: management and challenges. Lancet Gastroenterol Hepatol. 2020. DOI: 10.1016/S2468-1253(20)30057-1.

10. Xu L, Liu J, Lu M, Yang D, Zheng X. Liver injury during highly pathogenic human coronavirus infections. Liver Int. 2020. DOI: 10.1111/liv.14435. 